\title{
The Impending Alcohol Advertising Ban: Perceptions of Small Alcohol Retailers in Polokwane, South Africa - Lessons from the Advertising Ban on Tobacco Products
}

\author{
Malesela. W. Mogale \\ Olabanji. A. Oni \\ Tafadzwa Matiza
}

Department of Business Management, University of Limpopo, Turfloop Campus, Private Bag X1106, Sovenga, 0727, South Africa

Email: olabanji.oni@ul.ac.za

Doi:10.5901/mjss.2014.v5n15p21

\begin{abstract}
The paper presents the findings of a study conducted to establish the perceptions of small retailers of alcoholic beverages towards the proposed ban on alcoholic beverage advertising. The quantitative study sampled small retailers of alcoholic beverages base in Polokwane, South Africa. The survey data collection method was employed, with closed ended questionnaires being the instrument for the generation of the quantitative data. Data was analysed using SPSS version 20.0. From a study population of $\mathrm{N}=14$ it was established that retailers were generally aware of the proposed ban, which is similar to the ban instituted by the South African government on tobacco product advertising. Significantly, the study also found that the impact of advertising on the consumption of alcohol is minimal; with the proposed ban potentially having unintended negative effects other than the intended result. Based on its findings the study recommends that government focus on direct interventions to curb the abuse of alcohol rather that focus indirect interventions such as banning advertising of alcoholic beverages.
\end{abstract}

Keywords: Advertising, alcoholic beverages, small retailer, South Africa

\section{Introduction}

Advertising has been a long established approach to mass marketing communication and represents any paid-for form of communication by a company aimed at promoting the consumption of its product offering (Du Plessis, Van Heerden \& Cook, 2010). Alcoholic product advertising in the South African context is referred to as, any commercial communication or action brought to any member of the public in any manner with the aim, to effect or promoting the sale or use of any alcohol product (Government Gazette Amendment Act, 2008). However, as the societal marketing trend increases in prominence there has been a deliberate drive for responsible marketing practice. One such practice is the regulatory frameworks that 'outlaw' the advertising of products deemed to be harmful to society. Currently South Africa has a moratorium on the advertising of tobacco products, and according to the Government Gazette (2009: 523): "No person shall advertise tobacco products, including the use of tobacco trademarks, logos, and brand names or promote tobacco directly or indirectly through sponsorship or any other method".

The aim of this study is to determine the perceptions of small alcohol retailers towards the proposed ban of alcohol advertisements with particular reference to the existing regulation on tobacco product advertising. With this in mind the objectives of the study are to; a) Investigate the perception of small alcohol retail business owners towards the proposed alcohol advertising ban and; $b$ ) Determine whether the alcohol advertising ban would have an impact on the profitability of small alcoholic beverage retailers in Polokwane, South Africa. To accomplish these objectives the research sought to address the following research questions;

1. Are small alcoholic beverage retailers in Polokwane aware of the proposed ban of alcoholic product advertising?

2. What are the perceptions of small alcoholic beverage retailers in Polokwane towards the proposed ban?

3. Did the South African government consult small alcoholic beverage retailers in Polokwane in respect of banning alcohol advertisements? 


\section{Review of Related Literature}

Organizations in both the private and public sectors have learned that the ability to communicate effectively and efficiently with their target audiences is critical to their success (Blech \& Blech, 2003; Naeem, Bilal \& Naz, 2013:125-126). Advertising is not always aimed at directly selling a product or service but may be initiated to create awareness of products, to provide specific information, to establish or reinforce association and to build attitude or preferences (Blech \& Blech, 2003). According to Gitau (2012) advertising can be viewed as a catalyst in the hierarchy of effects which is the sequence of stages a prospective buyer goes through from initial awareness of a product (as a result of advertising) to the eventual action, either trial or adoption of a product.

\subsection{Tobacco Product Advertising}

The tobacco advertising ban as a basis for examining the social and economic impact on a similar ban on alcohol, proved to be difficult due to notable discrepancies such as laws prohibiting smoking different from laws prohibiting drinking. Also, the social unacceptability of smoking versus the social acceptability of alcohol consumption and the imprecise calculation of the effect of the advertising ban on smoking given the growing incidence of the consumption of contraband cigarettes in South Africa make an increase/decrease in the incidence of smoking immeasurable in real terms (Moerdyk, 2010).

A world health organization (WHO-2008), report found that, in its attempt to sell as many tobacco products as possible, the tobacco industry uses a great variety of direct and indirect approaches with the aim, effect or likely effect of promoting a tobacco product or tobacco use. These approaches can be broadly classified into two major groups:

- Any form of commercial communication, recommendation or action (tobacco advertising and promotion and

- Any form of contribution to any event, activity, or individual (tobacco sponsorship).

The Tobacco Products Control Amendment Act was passed in 1999, prohibiting all forms of advertising and promotion of tobacco products, including sponsorship and free distribution of tobacco products. The South African government gazette of 2008 states that

1. No person shall - a) Advertise, including the use of tobacco trademarks, logos, brand names and company names used on the tobacco products or; b) Use tobacco trademark, logos, brand names, or company names used on tobacco products for the purpose of advertising any organization, service activity, or event

2. No manufacturer, importer, distributor, or retailer of tobacco products shall; a) Organise or promote any organised activity that is to take place in whole or a part of the republic; b) Make any financial contribution to any organized activity that is to take place, or is taking or has taken place in the whole or in part of the republic.

\subsection{Effect of Tobacco Advertising and its prohibition thereof}

Tobacco advertising bans have become commonplace in developed nations but are less prevalent in developing countries. The importance of advertising bans as part of comprehensive tobacco control strategies has been emphasised by the Framework Convention on Tobacco Control which calls for comprehensive bans on tobacco advertising (Belcher, 2008). A WHO (2008) report on the tobacco 'epidemic' established a positive relationship between tobacco product advertising and the consumption of those products the report (ibid) also found that young people are particularly vulnerable to it and are the main target of brand stretching.

According to the Action on smoking and health fact sheet on tobacco advertising and promotion in the UK (2012), children and young people are more receptive than adults to tobacco advertising and that young people exposed to tobacco advertising and promotion are more likely to take up smoking. The 2012 research suggests that very young children understand that tobacco promotion is promoting smoking rather than a particular brand and that as they get older they can differentiate the brand messages. Many studies from the UK and elsewhere have shown that adolescents who smoke are more likely to be aware of and appreciate tobacco advertising than their non-smoking peers. Similarly, Blecher \& Nurhayati (2011) ascertain that tobacco companies use icons that attract adolescents. This is supported by advertisers that emphasize that smoking may enhance macho, brave, slang and modern image (Blecher \& Nurhayati, 2011). According to Belcher (2008), trends in consumption in developing and developed countries show that there has been a consistent decline in the consumption of tobacco products in high income countries. Similarly, Nelson (2003) believes that advertising restriction is only implemented by many governments once smoking prevalence has fallen to such levels that smokers are perceived no longer constitute an effective economic or political interest. 


\subsection{Proposed advertisement of alcohol ban}

The Government Gazette of 3 November 2008, published a proposed amendment of the National Road Traffic Regulations that states: No person may - (a) Display or cause to be displayed any liquor product advertisement or any advertisement depicting a liquor product visible on a public road, or permit it to be so displayed; (b) display any liquor product advertisement or any advertisement depicting a liquor product visible from a public road, on any land adjacent a public road or land separated from the public road by a street, or permit it to be so displayed. Should the proposed amendment be passed, it would mean that all alcohol product advertisements or any advertisement depicting alcohol products on billboards, street pole advertising, moving billboards, branded delivery vehicles, advertising on shop or factory fronts and any other form of advertising facing or visible from a public road will be banned.

Nelson (2010) ascertains that the effects of a ban of persuasive advertising also are uncertain. In a differentiated product industry, it's possible that advertising expenditures are so large that an advertising ban reduces costs and product prices, thereby offsetting or defeating the purpose of the ban. For products that are well known to consumer's also known as mature products, the presumption is that advertising primarily affects brand shares and has little impact on primary demand. However, a study done by Jiang \& Ling(2011) is certain that tobacco advertising significantly increases tobacco sales, but conversely banning advertising leads to a reduction in consumption. Hastings, (2005), highlights the evidence from advertising and consumption in a number of studies in particular using data from the National Longitudinal Survey of Youth 1997; he found that a $28 \%$ reduction in alcohol advertising would reduce adolescent monthly participation from $25 \%$ to between 24 and $21 \%$ a significant change.

According to Neville (2013) an advertising ban on alcohol will not have the intended impact of reducing consumption of alcoholic beverages, while Dickerson and Dorsett (2004) with particular reference to the United Kingdom, emphasise the perception that banning of alcohol advertisement does not affect consumption, positing that alcohol advertising either does not increase total alcohol consumption, or has an impact that is, in the case of beer advertising, so marginal as to be insignificant.

A study on European states found that alcohol advertising is effective and that it increases consumption, thereby contributing to a widespread problem for European societies. However, the same study also concluded that the prohibition of alcohol advertisements indeed affected the consumption of alcohol determining that national prohibition on advertising succeeded in lowering consumption (Jack \& Blocker, 2006).

\section{Methodology}

The study was quantitative in nature with primary data being generated through personal administered questionnaires containing a set of structured, focused questions that employ a self-reporting paper and pencil format (Salkind, 2012). In this study the questionnaire consisted of a combination of relevant questions and checklists. The questionnaire composed of closed ended questions that were compiled in English. With regard to the questionnaire, translated questions to Sepedi were availed to aid in data collection for non-English speaking respondents.

The focus area of the study was Polokwane which is the capital of Limpopo Province, of South Africa. The central business district of Polokwane was the main focus area of the study which is the commercial area of the city. The area was selected because the area accommodates numerous small retailers who are the subjects of this study. Snow ball sampling, a non-probability sampling technique was implemented and initial study subjects recruited future subjects from among their acquaintances. The final population of $N=20$ small retailers was built up, this represented enough prospects to allow for a useful research (Fatoki \& Chiliy, 2012).

Questionnaires were deployed at the data generation instrument, composed of closed ended questions in the following sections: Section A: Demographic questions; Section B: Awareness of the proposed alcohol ban and; Section C: Perception of respondents towards the proposed ban of alcohol beverage advertisement. The 5-point Likert scale was adopted for the predetermined responses. The Statistical Package for Social Sciences (SPSS) 20.0 was utilised to analyse the data generated by the study. Gerber-Nel, Nel, and Kotze, (2005) note that descriptive statistics are used to describe the basic features of the data in a study. Descriptive statistics are used to in this study to describe the main features of the quantitative data that was collected. Descriptive statistics provide simple summaries about the sample and the measures of this study and together with simple graphics analysis; they form the basis of quantitative analysis of the data. 


\section{Results of the Study}

\subsection{Response rate}

Twenty questionnaires were distributed in the Polokwane central business district, and 14 questionnaires were returned, recording a 70\% response rate. According to Bryman and Bell (2011) response rates above 60\% are acceptable in business research.

\subsection{Demographic data}

The demographic variables for which data was collected and information obtained included age educational qualification and nationality of the respondents, length of operation in years and the ownership of the business. Figure 1 reflects three demographic variables, gender, nationality, and ownership.

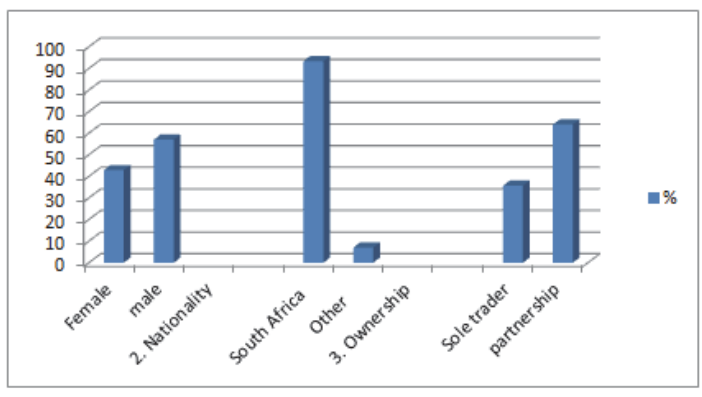

Figure 1: Summary of demographic data

The results indicated respondents are split 57\% male and $43 \%$ female. Majority of the respondents (93\% were South African and a minority of $7 \%$ is the other) and $36 \%$ of the respondent's business ownership are sole traders while $64 \%$ are partnerships.50\% of the respondent were between the age of $20-30$ years and the other $50 \%$ are between the age of 30-40 years amongst the 14 questionnaire returned none of the respondents were between the age of 40 years and older. The results also indicate that most respondents (50\% of respondents) had post matric qualifications, these include diploma, degree and post graduate $29 \%$ of the respondents had obtained senior matric certificate, the remaining $21 \%$ of the respondents had not obtained matric level, this implies that the respondents were well educated and were able to give informed responses to the questions.

\subsection{Awareness of the proposed on alcoholic beverage advertising}

This section of the study sought to generate data regarding the awareness of the proposed ban on advertising alcoholic beverages amongst small alcohol retailers based in Polokwane. The results are summarised in Table 1.

Table 1: Awareness of the proposed alcohol ban - Closed question responses

\begin{tabular}{|l|c|c|c|c|c|}
\hline & \multicolumn{2}{|c|}{ Yes } & \multicolumn{2}{|c|}{ No } & \\
\hline & Frequency & $\begin{array}{c}\% \text { Freq } \\
\mathrm{N}=14\end{array}$ & Frequency & $\begin{array}{c}\% \text { Freq } \\
\text { N=14 }\end{array}$ & $\begin{array}{c}\text { Total } \\
\% \text { Freq }\end{array}$ \\
\hline Are you aware that cigarette advertisements have been banned? & 14 & 100.00 & 0 & 0.00 & 100 \\
\hline Are you aware of the proposed alcohol advertisements ban? & 9 & 64.285 & 5 & 35.714 & 100 \\
\hline $\begin{array}{l}\text { Do you know the reasons for the proposed alcohol ban, if yes, please } \\
\text { elaborate? }\end{array}$ & 5 & 35.714 & 9 & 64.285 & 100 \\
\hline Are you aware of the risk associate with the use of alcohol beverages? & 9 & 64.285 & 5 & 35.714 & 100 \\
\hline Do you think it is necessary to advertise alcohol beverages? & 8 & 57.143 & 6 & 42.857 & 100 \\
\hline
\end{tabular}

The results indicate that all the respondents (100\%) were aware of the ban on tobacco (cigarette) advertising in South 
Africa. However, only $64 \%$ of respondents were aware of the proposed ban on alcohol advertisements, with $36 \%$ not being aware. This implies that there has not been wide government consultation and adequate awareness programs for alcoholic product retailers. Of the $64 \%$ who were aware of the proposed ban, only $36 \%$ were aware of the reasons for the proposed ban, while the majority of respondents (64\%) were not aware of these reasons, again suggesting limited communication from the government to small retailers.

The results also indicate that the majority of respondents (64\%) knew of the risks associated with the consumption (use) of alcoholic beverages, while the minority (35\%) claimed not to be aware of the risks associated with the consumption of their products. Interestingly a small majority of respondents (57\%) believed that it was necessary to advertise alcoholic beverages to consumers, while (43\%) believed that it was not necessary to advertise alcohol. This raises questions on the validity of the perceived significant impact of advertising on alcohol consumption.

\subsection{Perceptions of small-scale retailers regarding the effect of alcohol and the proposed advertising ban}

This section of the study sought to generate data regarding the perceptions of small retailers towards the influence of advertising on alcohol consumption and how they perceive the impact of advertising and its ban there-of on sales and consumption. The results are summarised in Table 2.

Table 2: Reaction towards the perception regarding the proposed alcohol beverage advertisement ban -Likert Scale Responses \& Frequencies

\begin{tabular}{|l|c|c|c|c|c|c|c|c|}
\hline & $\% S A$ & $\% A$ & $\% \mathrm{~N}$ & $\% \mathrm{D}$ & $\% \mathrm{SD}$ & Cum \% & Mean & Std Deviation \\
\hline Advertising has a positive influence on consumers to consume alcohol. & 21 & $\mathbf{2 9}$ & $\mathbf{2 9}$ & 21 & $\mathbf{0 . 0}$ & 100 & 2.50 & 1.092 \\
\hline Alcohol advertising encourages people under the age of 18 to consume alcohol. & 28 & 7 & 21 & 29 & 14 & 100 & 2.93 & 1.492 \\
\hline The ban of alcohol beverages advertising will have a negative impact on sales. & 29 & 21 & 29 & 14 & 7 & 100 & 2.50 & 1.286 \\
\hline Advertising is the main reason people consume alcohol. & 29 & 14 & 14 & 0 & 43 & 100 & 3.14 & 1.791 \\
\hline
\end{tabular}

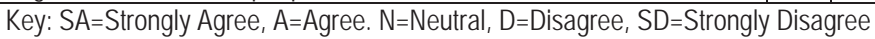

A combined $50 \%$ of respondents believed that advertising positively influences consumers to consume alcohol, while $29 \%$ were neutral and $21 \%$ did not believe that advertising had such an influence. This result shows how considerable the debate of the significance advertising to the consumption of alcoholic beverages is. Significantly the study found that respondents did not believe that alcohol related advertising encouraged under-age drinking. 29\% disagreed, with $14 \%$ strongly disagreeing with the statement. Conversely $28 \%$ of the respondents strongly agreed with the statement with $7 \%$ agreeing. This result again illustrates the divisive nature of the debate of the influence of advertising on influencing the consumption of alcohol.

With regards to the ban of advertising having a negative impact on the sales of small retailers, the results indicate the majority of retailers (29\%) believed that a ban on advertising would have a negative impact on their sales. Similarly, (29\%) were neutral with regards to the statement, while $14 \%$ and $7 \%$ disagreed and strongly disagreed with the statement respectively. The results indicate that while most respondents perceive that the proposed ban will have a negative impact on sales, the same number of respondents was not sure whether the ban would have an impact on their sale at all. The majority of respondents (42\%) strongly disagreed with the statement that advertising is the main reason why people consume alcohol, thereby down-playing the perceived significance of alcohol advertising. On the other hand $29 \%$ and $14 \%$ of the respondents strongly agree and agree with the statement respectively. $14 \%$ were neutral with regards to the statement neither agreeing nor disagreeing with the view that advertising was the reason people consumed alcohol.

\section{Discussion and Conclusions}

As a result of this study it emerged that on average the small alcoholic beverage retailer in Polokwane was aware of the proposed ban on alcoholic beverage adverting. Significantly, all respondents were well aware of the ban on cigarette advertising. Unlike with tobacco products, the reasons for the ban on alcohol advertising are not known to most retailers although they were aware of the risks associated with the consumption of alcohol. This study also found that respondents felt that the advertising of alcoholic beverages is necessary although, Nelson (2010) ascertains that the effects of a ban of persuasive advertising also are uncertain.

The study also found that respondents believed that advertising positively influenced the consumption of alcoholic 
beverages. A study by Jiang \& Ling (2011) found that tobacco advertising significantly increased tobacco sales and conversely a ban on advertising also reduced consumption. With particular reference to alcohol advertising, Neville (2013) suggests that an advertising ban on alcohol will not have the intended impact of reducing consumption of alcoholic beverages, while Dickerson and Dorsett (2004) with particular reference to the United Kingdom, emphasise that a ban on advertising alcohol does not have a direct effect on alcohol consumption and that its effect is so marginal as to be insignificant.

Although the respondents did not believe that advertising encouraged under-age drinking, a study by Hastings (2005) found that a $28 \%$ reduction in alcohol advertising would reduce adolescent monthly participation from $25 \%$ to between 24 and $21 \%$ and represents a significant change in adolescent behaviour. With particular reference to the effect of the proposed ban on retail sales would have a negative effect on sales. One may suggest that an imposed advertising ban would have a direct impact on small retailers mainly reliant on the outdoor advertising such as billboards for advertising. Hardship, job-losses, and liquidations are the realities that small retailers may face as a result of a direct ban on alcoholic beverage advertising.

The findings of the quantitative research conducted suggest that alcohol advertising does not play a significant role in a person deciding to consume alcohol and has little or no effect on alcohol consumption in South Africa. Advertising merely promotes individual brands. The government should consider other policy measures to inhibit the harmful use of alcohol. Most of the alcohol consumed is not advertised, only a handful of brands are broadcasted, therefore, there is insufficient evidence to support an association between advertising, and patterns of consumption of alcohol in South Africa. Based on the mentioned findings, there is insufficient, evidence to support the view that alcoholic beverage advertising has a significant impact on the rate of alcohol abuse and alcoholism. Accordingly, the potential economic impact of the alcohol advertising ban, total losses of up to R2.6bn in sponsorships and advertising spend (Moerdyk, 2010) far more out-weighs the intended effect, and rather a set of carefully targeted policies, restrictions, and laws covering a range of measures far wider than advertising would be preferable and should be taken into consideration and should be introduced, regulated and monitored cautiously.

The potential job losses in advertising and media companies and downstream industries are significant. The negative impact on the financing of major and peripheral sporting codes such as football and cricket, and South Africa's ability to host international sporting events will be hampered, as the majority of the sporting events are sponsored by alcoholic beverage brands. It is therefore recommended that government; focus on fighting the harmful use of alcohol abuse, by targeting those with problematic drinking patterns and understanding the factors leading to their inappropriate alcohol consumption, alcohol abuse and its consequences can be significantly reduced. Government and the alcoholic beverage industry should commit to developing, implementing, and supporting a broad setup of targeted intervention programs to achieve substantial reductions in irresponsible consumption and a substantial improvement in public health. More visible permanent government led media campaigns should be initiated targeting the problem areas and marketing and advertising related to alcoholic beverages be left in place.

\section{References}

Action on Smoking and Health (2012). Tobacco advertising and promotion in the UK. [Online] Available: http://ash.org.uk/information/facts-and-stats/fact-sheets. (Accessed August 10, 2013).

Belch G. E, and Belch M. A. (2003). Advertising and promotion, an integrated marketing communication perspective, 6th Ed. Mc-Hill Companies.

Blecher E. (2008). Impact of tobacco advertising ban on consumption in developing countries, Journal of Health Economics, (27), pp. 930.

Dickerson, S \& Dorsett, J (2004). Advertising and alcohol consumption in the UK, International Journal of Advertising (23), pp. 172

Du Plessis, F, V man Heerden, N \&Cook, and G. (2010). Integrated marketing communication, 3rd Ed. Pretoria: Van Schaik.

Fatoki O. \& Chiliy W. (2012). An investigation into the attitudes towards business ethics by local and emigrant SME owners. Journal of Social Sciences, 32(1): 13-21.

Gerber-Nel, C., Nel, D. \& Kotze, T. (2005). Marketing research. Claremont: New Africa Books (Pty) Ltd.

Gitau J. (2012). Effects of advertising on Small and medium enterprises in Kenya. A case study of the East African packaging industries. Thesis Business Management, Laurea University of Applied Sciences.

Government Gazette, South Africa (2008). (512) 302821. [Online] Available: http://www.greengazette.co.zal. (Accessed August 10, 2013).

Hastings, H, Anderson, S, Cooke, E \& Gordon R. (2005). Alcohol marketing and young people drinking: a review of the research. Journal of the Public Health, 26(3), pp 269-311.

Jack, S \& Blocker J R. (2006). Did prohibition really work alcohol prohibition as a public health innovation 96(2), pp233-243.

Jiang, N \& Ling, P.M. (2011). Reinforcement of smoking and drinking: Tobacco marketing strategies with alcohol in the USA. Journal of 
the Public. 101(10), pp54.

Moerdyk, C.J. (2010). Summary of a preminalry impact study on a complete ban of alcohol advertising. Institute of Marketing Management. [Online] Available: http://www.ara.co.za/FE82D031-C5B9-4BE0-9F0C-C54CCBA7555C/Fina IDownload/Downloadld-2AD7D574677747FFDA43AF0F8E3479AE/FE82D031-C5B9-4BE0-9F0C-

C54CCBA7555C/uploads/complete-ban-on-alcohol-advertisement.pdf (Accessed August 10, 2013).

Nelson J.P. (2003). Cigarette demand, structural change, and advertising bans: international evidence, contributions to economic analysis and policy. Contributions to Economic Analysis and Policy, 2(1).

Nelson, P. 2010. Advertising Bans in the United States," EH.Net Encyclopaedia, edited by R. Whaples, May 2004, pp.1-29. [Online] Available: http://eh.net/encyclopedia/?article=Nelson.AdBans. (Accessed August 18, 2013).

Nevil, Glenda. (2013). Impact! What an alcohol advertising ban would do the economy. [Online] Available:http://themediaonline.co.za/2013/06/impact-what-an-alcohol-advertising-ban-would-do-to-the-economy. (Accessed July 13, 2013)

Salkind, N.J. (2012). Exploring research, 8th Ed. United States of America: Pearson Education, Inc.

World Health Organisation (2008). The global report on tobacco epidemic, Switzerland. [Online] Available: www.who.int/tobacco/ mpower/mpower_report_full_2008.pdf (Accessed August 18, 2013). 